$11-26-2012$

\title{
Canopy vs. Roots: Production and Destruction of Variability in Soil Moisture and Hydrologic Fluxes
}

Andrew J. Guswa

Smith College, aguswa@smith.edu

Follow this and additional works at: https://scholarworks.smith.edu/egr_facpubs

Part of the Engineering Commons

\section{Recommended Citation}

Guswa, Andrew J., "Canopy vs. Roots: Production and Destruction of Variability in Soil Moisture and Hydrologic Fluxes" (2012). Engineering: Faculty Publications, Smith College, Northampton, MA. https://scholarworks.smith.edu/egr_facpubs/31 
Special Section: Soil-PlantAtmosphere Continuum

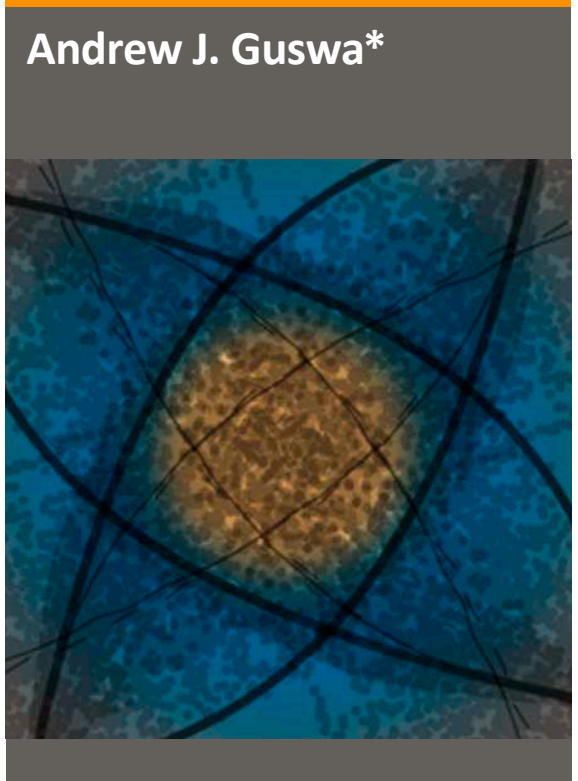

Plants redistribute precipitation and create spatial variability in soil mois-

ture through canopy interception

and, at the same time, homogenize

soil moisture and undo the variabil-

ity through root uptake. Through a modeling study driven by stochastic rainfall, the effects of these competing processes on the water balance, localization of recharge, and the temporal and spatial variability of soil moisture are explored. While in some cases the root processes can mitigate the effects due to canopy interception, in others the canopy effects dominate.

A.J. Guswa, Picker Engineering Program, Smith College, Northampton, MA 01063. *Corresponding author (aguswa@smith.edu).

Vadose Zone J.

doi:10.2136/vzj2011.0159

Received 7 Nov. 2011.

(c) Soil Science Society of America

5585 Guilford Rd., Madison, WI 53711 USA. All rights reserved. No part of this periodical may be reproduced or transmitted in any form or by any means, electronic or mechanical, including photocopying, recording, or any information storage tocopying, recording, or any information storage and retrieval system, without permission in writing
from the publisher.

\section{Canopy vs. Roots: Production and Destruction of Variability in Soil Moisture and Hydrologic Fluxes}

The leaves and stems of forest canopies intercept and redistribute precipitation in space. Many investigations have demonstrated that spatial patterns of throughfall and stemflow are persistent in time, and this produces wet and dry spots in the soil. At the same time, root uptake for transpiration acts to destroy this variability. This homogenization is enhanced by root compensation (extraction at high rates from wet regions) and hydraulic redistribution (transport of water from wet soils to dry via the roots). Because many hydrologic and biogeochemical processes are nonlinear functions of soil moisture, an understanding of the relative strength of the production and destruction of spatial variability is necessary to represent those processes at larger scales. The creation and reduction of spatial variability is investigated through stochastic modeling of soil-moisture dynamics. This work investigated the combined effects of canopy interception and root uptake on the water balance, the localization of recharge, the variability of soil moisture in time and space, and the upscaled relationship between plant uptake and mean soil moisture. Interception and plant uptake counterbalance each other to some extent with respect to the water balance and average hydrologic fluxes, although there may be some conditions for which one process dominates. In contrast, canopy interception has a noticeable effect on recharge localization and the horizontal variability of soil moisture that cannot be undone by root processes. Thus, this variability may need to be accounted for to properly represent biogeochemical processes that are nonlinear functions of soil moisture. In all cases, the particular results depend on the strength of the canopy and root processes, along with the characteristics of climate, soil, and vegetation.

Many hydrologic and biogeochemical processes occurring in the vadose zone are nonlinear functions of soil moisture. As a result, they depend not only on average values of soil moisture but also on the character of its variability in space and time. An understanding of the production and destruction of this variability is required to properly understand and represent ecohydrologic processes across scales. The structure and function of vegetation presents a compelling puzzle in this regard because leaves and stems increase the spatial variability of water fluxes while roots act to homogenize soil moisture. Who wins in this competition and what are the effects?

Field studies show that canopy interception redistributes water in space, creating patterns of distinct wet and dry spots that persist through time. These spatial patterns vary among species and plant functional type and propagate through to soil moisture, recharge, and geochemical fluxes. At the same time, water uptake for transpiration acts to homogenize soil moisture within the root zone, and a number of field and laboratory investigations have demonstrated that some plants can actively redistribute water via their roots. If strong enough, the belowground processes have the potential to mitigate or undo the heterogeneity introduced by canopy interception. Through a set of numerical experiments, this work investigated the combined effects of canopy interception and root uptake on the water balance, the localization of recharge, the variability of soil moisture in time and space, and the upscaled relationship between plant uptake and mean soil moisture.

\section{Background}

\section{Throughfall Variability and Persistence}

Precipitation that falls on vegetated surfaces is first filtered by plant canopies, which retain and redistribute water. Water that makes its way to the forest floor is separated into two components: throughfall-the water that passes through or drips from canopy leaves and branches, and stemflow-the water that funnels down the stem of a plant. In most cases, 
throughfall is a far larger component of the forest water balance, and the combination of throughfall and stemflow is usually less than the incident precipitation (notable exceptions occur in cloud forests). A variety of biotic and abiotic factors affect the amount of water intercepted and evaporated directly from the canopy (e.g., Levia and Frost, 2003, 2006), and a number of models have been developed to predict mean interception based on vegetation characteristics and meteorologic conditions (e.g., Liu, 2001; Gash et al., 1995; Gash, 1979; Rutter et al., 1971).

Additionally, vegetation canopies act to redistribute water in space, and many throughfall investigations have focused on characterizing this variability. From these studies, some common themes have emerged. First is that spatial patterns are temporally persistent, even across seasons and years (Guswa and Spence, 2012; Gerrits et al., 2010; Zimmermann et al., 2009; Shachnovich et al., 2008; Keim et al., 2005; Guswa and Rhodes, 2004; Nadkarni and Sumera, 2004; Gomez et al., 2002; Raat et al., 2002; Whelan and Anderson, 1996), and spatial correlation is weak. In many studies, spatial correlation is nonexistent or below the sampling resolution (e.g., Guswa and Rhodes, 2004; Gomez et al., 2002; Loustau et al., 1992). In a detailed study, Zimmermann et al. (2009) found correlation lengths for seven out of 14 events to be $<2 \mathrm{~m}$; for the other events with longer correlation lengths, the nugget component of the variogram represented more than half of the total variability. Spatial coefficients of variation approach stable and consistent values around 15 to $30 \%$ for large rain events and accumulations of precipitation with time (e.g., Guswa and Spence, 2012; Keim et al., 2005; Carlyle-Moses et al., 2004; Raat et al., 2002; Loustau et al., 1992). Spatial distributions are often positively skewed, with a few very wet spots beneath canopy drip points (Guswa and Spence, 2012; Zimmermann et al., 2009; Ziegler et al., 2009; Ford and Deans, 1978), although Guswa and Spence (2012) found distributions with slightly negative skewness values under hemlock [Tsuga canadensis (L.) Carrière] stands. Lastly, specific field studies have shown that the spatial patterns of throughfall propagate to soil moisture (Schume et al., 2003; Raat et al., 2002), plant uptake (Bouten et al., 1992; Ford and Deans, 1978), and recharge and leaching (Nikodem et al., 2010; Chang and Matzner, 2000; Manderscheid and Matzner, 1995; Bouten et al., 1992).

\section{Root Uptake}

Contrary to the vegetation canopy, which, as discussed above, generates spatial variability, plant roots and the uptake of water for transpiration act to homogenize soil moisture (cf., Ivanov et al., 2010; Katul et al., 1997; Breazeale, 1930). As water is withdrawn from the soil column, uptake from dry areas slows down or stops as the moisture becomes unavailable to the plant; uptake continues from wet areas and thus drives the system toward a uniform dryness. In some plants, this homogenization is amplified by two behaviors: root compensation and hydraulic redistribution (e.g., Katul and Siqueira, 2010).
When resistance to water flow in their roots is low, plants may extract water at a high rate from wetter soils to compensate for part of the root system being dry. That is, water can be extracted from a wet region at a rate that is higher than what would be needed to meet transpiration demand on a per-root basis. The magnitude of this compensating behavior varies from plant to plant. Split-root and localized irrigation experiments have documented that in some cases this compensation may be minimal, whereas in others it may be that a plant can meet transpiration demand when only half of its roots are extracting water (Kang et al., 2003; Yao et al., 2001; Croker et al., 1998; Fort et al., 1998; Green et al., 1997; Auge et al., 1995; Khalil and Grace, 1993; Neales et al., 1989).

Additionally, some plants will not only compensate for heterogeneous soil moisture via enhanced uptake but will also move water from wet to dry soil through their root systems-a process known as hydraulic redistribution or hydraulic lift. Initially demonstrated for the upward movement of water by sagebrush (Artemisia tridentata Nutt.) from deep, wet layers to the surface (Caldwell and Richards, 1989; Richards and Caldwell, 1987), evidence now exists for the upward and downward flow of water for herbs, grasses, shrubs, and trees across a range of climates (e.g., Domec et al., 2010; Oliveira et al., 2005; Burgess et al., 1998; Caldwell et al., 1998; Dawson, 1993). In additional to the vertical movement of water, recent investigations have also demonstrated lateral redistribution of soil moisture (e.g., Nadezhdina et al., 2009; Burgess and Belby, 2006). As with root compensation, the strength of this phenomenon varies from plant to plant. Some vegetation exhibits little or no ability to redistribute water (e.g., Espino and Schenk, 2009), and, in other cases, water fluxes due to hydraulic redistribution can amount to 20 to $25 \%$ of daily water use (Domec et al., 2010; Emerman and Dawson, 1996).

Both root compensation and hydraulic redistribution amplify the homogenizing effect of plant uptake on soil moisture. In so doing, transpiration and ecosystem productivity can be enhanced (e.g., Domec et al., 2010; Katul and Siqueira, 2010; Ryel et al., 2002), although redistribution of moisture does not always lead to increased transpiration (Nadezhdina et al., 2009). In either case, these root processes will mitigate the spatial variability of hydrologic fluxes and soil moisture introduced by the canopy.

\section{Approach}

In this modeling effort, the representation of processes was kept consistent with the questions being asked and simple enough so that the results could be attributed to specific aspects of the system. This work focused on determining stand-scale fluxes and characteristics that are influenced by the spatial variability of throughfall and hydraulic redistribution at the sub-stand scale. To maintain this focus, the project considered a relatively flat vegetation patch, and all lateral flows except for hydraulic redistribution were neglected. While previous work has shown that such a simplification is 
justifiable for some environments (Siqueira et al., 2008; Vrugt et al., 2001; Katul et al., 1997), it did limit the scope of this work because lateral fluxes can be significant components of the local water balance in areas of moderate to high topographic relief.

This simplification enabled the forest floor to be represented by a set of one-dimensional models of soil moisture, coupled to each other via the root network. Rainfall was represented as a stochastic process, and the spatial variability of throughfall was captured by a distribution of infiltration forcing across these one-dimensional models. Soil moisture in each column was subsequently withdrawn and redistributed by plant roots. Because the emphasis was on the timing and variability of throughfall events and hydraulic redistribution, a semi-daily time scale was used to capture efficiently the dynamics of these processes.

A layered model allows the explicit representation of vertical variability in processes and parameters throughout the root zone. The evolution of soil moisture in space and time can be represented by a volume-balance equation, modified to account for plant uptake and redistribution:

$$
\frac{\partial[n S(z, t)]}{\partial t}=-\frac{\partial q(z, t)}{\partial z}-u(z, t)
$$

where $S$ is the local saturation, $n$ is porosity, $q$ is vertical soilmoisture flux, $u$ is the local sink or source due to plant uptake or redistribution with dimensions of depth per depth per time, $z$ is the vertical coordinate, and $t$ is time. For solution, Eq. [1] must be coupled with initial and boundary conditions, a relationship or set of relationships between flux and local saturation, and an expression for plant uptake.

\section{Throughfall}

To capture the effects of precipitation frequency and intensity on the production and destruction of soil moisture variability, throughfall events were represented as a stochastic process. Precipitation events were characterized by a frequency, $\lambda^{*}$, and exponentially distributed depths with mean $\alpha$. With a focus on closed canopy systems, interception was represented by a threshold depth, $\Delta$, such that the spatially averaged throughfall depth $\overline{\mathrm{TF}}_{i}$ for a given rain event of magnitude $P_{i}$ is

$$
\overline{\mathrm{TF}_{i}}=\max \left(0, P_{i}-\Delta\right)
$$

That is, all precipitation up to the threshold, $\Delta$, is intercepted by the canopy, and all additional water generates throughfall, a representation supported by field data (Guswa and Spence, 2012). This leads to a representation of throughfall as a stochastic process with mean depth $\alpha$ and frequency given by $\lambda=\lambda^{*} \exp \left(-\frac{\Delta}{\alpha}\right)$

as in Rodriguez-Iturbe et al. (1999).

For each event, the spatial distribution of throughfall depths is modeled with a Gamma distribution with a mean equal to $\overline{\mathrm{TF}_{i}}$ and a coefficient of variation, $\mathrm{CV}$, which was taken to be constant across all events (cf., Guswa and Spence, 2012). The Gamma distribution was chosen because it is a parsimonious distribution, defined completely by its mean and coefficient of variation, is bounded by zero, and has a slightly positive skew. The spatial variability is represented as being perfectly persistent through time such that the relative wetness of a given location remains constant. That is, a location that receives throughfall equal to the 90th percentile of the distribution for one event would receive throughfall depths corresponding to the 90 th percentile for all events.

\section{Soil-Moisture Dynamics and Recharge}

Once throughfall is generated, all water enters the soil column; this model does not consider the generation of overland flow. Infiltration is considered to be fast relative to the daily time scale, a simplification that is appropriate for soils without significant clay (e.g., Melone et al., 2006). This allows infiltration to be represented as instantaneous shots of water added to the root zone.

Local throughfall fills each soil column from the top down, bringing the saturation of each layer to field capacity. This process proceeds until all of the incoming water is used up or the entire root zone is saturated to field capacity, at which point any excess water is considered to be recharge. After infiltration, the subsequent capillary movement of water between soil layers is neglected in deference to the removal or supply via plant roots (e.g., Struthers et al., 2006; Guswa et al., 2004). These simplifications retain the spatial variability of soil moisture throughout the root zone and eliminate the cost of resolving soil-moisture redistribution at short time scales.

\section{Plant Uptake and Hydraulic Redistribution}

The representation of plant uptake encompasses two related behaviors: root compensation and hydraulic redistribution (see above). Root compensation refers to the ability of a plant to withdraw water from wetter soils at a high rate to compensate for a lack of water in other parts of the root zone. Hydraulic redistribution refers to the actual movement of water from wet to dry parts of the soil via the root system.

Plant uptake and these behaviors are modeled by an electric circuit analogy, following the early work of Gardner (1960) and Cowan (1965) and subsequent extensions (e.g., Li et al., 2001; Lhomme, 1998; Shani and Dudley, 1996; Cardon and Letey, 1992; Federer, 1979, 1982; Herkelrath et al., 1977). Plant uptake is proportional 
to a difference in water potential between the soil and the plant, and the movement of water from the soil into the plant is limited by two resistances: one associated with the movement of the water through the soil to the roots and one associated with water movement through the root and plant tissue. The local uptake function is described mathematically by

$$
u(z, t)=\operatorname{RLD}(z) \frac{\Psi[S(z, t)]-\Psi_{\mathrm{p}}(t)}{R_{\mathrm{s}}[S(z, t)]+R_{\mathrm{r}}}
$$

where RLD is the local root-length density ( $\mathrm{mm}$ roots $\mathrm{mm}^{-3}$ soil), $\Psi$ is the water potential in the soil, and $\Psi_{\mathrm{p}}$ is the plant (stem) water potential, $R_{\mathrm{s}}$ is the soil resistance (inversely proportional to the unsaturated conductivity), and $R_{\mathrm{r}}$ is the root resistance (e.g., Larcher, 1995; Lhomme, 1998). The local density of roots as a function of depth is represented as a truncated exponential (cf., S. Tron, personal communication, 2011; Jackson et al., 1996):

$$
\operatorname{RLD}(z)=\overline{\operatorname{RLD}} \frac{\left(1 / Z_{\text {scale }}\right) \exp \left[-\left(z / Z_{\text {scale }}\right)\right]}{1-\exp \left[-\left(Z_{\mathrm{r}} / Z_{\text {scale }}\right)\right]}
$$

where $\overline{\mathrm{RLD}}$ is the mean root-length density throughout the root zone, and $Z_{\mathrm{r}}$ is the maximum root depth, $Z_{\text {scale }}$ is a scale factor that approaches the mean root depth as $Z_{\mathrm{r}} / Z_{\text {scale }}$ increases. Water potential and saturation are related by

$$
\Psi(S)=\Psi_{\mathrm{e}}\left(\frac{S-S_{\mathrm{h}}}{1-S_{\mathrm{h}}}\right)^{-b}
$$

where $\Psi_{\mathrm{e}}$ is the air-entry pressure, $S_{\mathrm{h}}$ is the hygroscopic saturation, and $b$ is a shape parameter (Clapp and Hornberger, 1978).

The total transpiration rate is obtained by integrating $u(z, t)$ (Eq. [4]) over the root zone. In unstressed conditions, actual transpiration equals the potential rate. As the soil dries out, however, the plant will begin to close its stomata to reduce transpiration and prevent damage to its tissues. In the model presented here, the functioning of plant stomata and the associated vulnerability curve are not represented explicitly. Rather a critical plant potential is determined, herein referred to as the wilting potential, $\Psi_{\mathrm{w}}$; the plant potential, $\Psi_{\mathrm{p}}$, is constrained to remain above this value. Therefore, no water will be taken up from soils at the wilting potential, $\Psi_{\mathrm{w}}$, making $S_{\mathrm{w}}$ a lower limit on soil moisture.

Because of the branching nature of roots, water flows from the soil to the plant via a number of parallel pathways. With multiple paths for uptake, the root system can compensate for spatial variations in soil moisture by extracting water from wet regions at a high rate. The ability to do so is a function of the magnitude of the root resistance term in Eq. [4] because the soil resistance is negligible at higher saturations. If the root resistance is small, the plant can extract water at high rates from wet regions to compensate for portions of the root zone that are dry. This behavior can be expressed by a factor, $\gamma$, where $1 / \gamma$ is defined as the minimum fraction of the roots that must be in wet soil (at field capacity) in order for the plant to withdraw enough water to meet the transpiration demand if extraction from elsewhere in the soil column is zero (e.g., Guswa et al., 2002, 2004). Note that this compensation parameter, $\gamma$, is not something added to the model presented in Eq. [4]. It is defined as

$\gamma=\frac{Z_{\mathrm{r}}}{T_{\mathrm{pot}}} \frac{\left(\Psi_{\mathrm{fc}}-\Psi_{\mathrm{w}}\right)}{R_{\mathrm{r}}}$

where $\Psi_{\mathrm{fc}}$ is the water potential at field capacity and $T_{\mathrm{pot}}$ is the potential transpiration. The parameter $\gamma$ is a way of intuitively expressing the effect of the root resistance on plant compensation. Split-root experiments have indicated that the values of this parameter can range from 1 to >2 (e.g., Yao et al., 2001; Croker et al., 1998; Fort et al., 1998; Green et al., 1997; Auge et al., 1995; Khalil and Grace, 1993; Neales et al., 1989). Of course, even though local uptake can provide water at high rates, the total uptake, i.e., the integral of Eq. [4] over the root zone, is constrained to be less than or equal to $T_{\text {pot }}$ by adjusting $\Psi_{\mathrm{p}}$.

In addition to accounting for this compensating behavior, the formulation of plant uptake given by Eq. [4] can also represent hydraulic redistribution, the movement of water from wet to dry regions of the soil via the root system. This will occur at those locations for which $\Psi<\Psi_{\mathrm{p}}$; that is, locations where the soil-water potential is less than the plant potential. This is unlikely to occur during the day, when the plant is transpiring and the plant potential is low, but can occur at night when the plant-water potential increases. More and more investigations are demonstrating the significance of this process in the field (see above).

To effectively represent this process, each day is separated into a daytime and a nighttime period, and water uptake during the daytime is as described above. To simulate hydraulic redistribution at night, the plant-water potential is set to the value that produces a net zero flux across all roots, i.e., across all soil layers across all of the coupled one-dimensional models. This assures that water is conserved within the root zone, and the nighttime flux of water to or from a patch of soil is then given by Eq. [4]. This redistribution may occur vertically within a soil column and horizontally across columns. This formulation is consistent with stem-mediated hydraulic redistribution (e.g., Nadezhdina et al., 2009; Burgess and Belby, 2006) and implies that each point in the soil is hydraulically connected to every other-a simplification that increases the efficiency of the redistribution. Thus, the pairing of this model with one that does not permit hydraulic redistribution will represent 


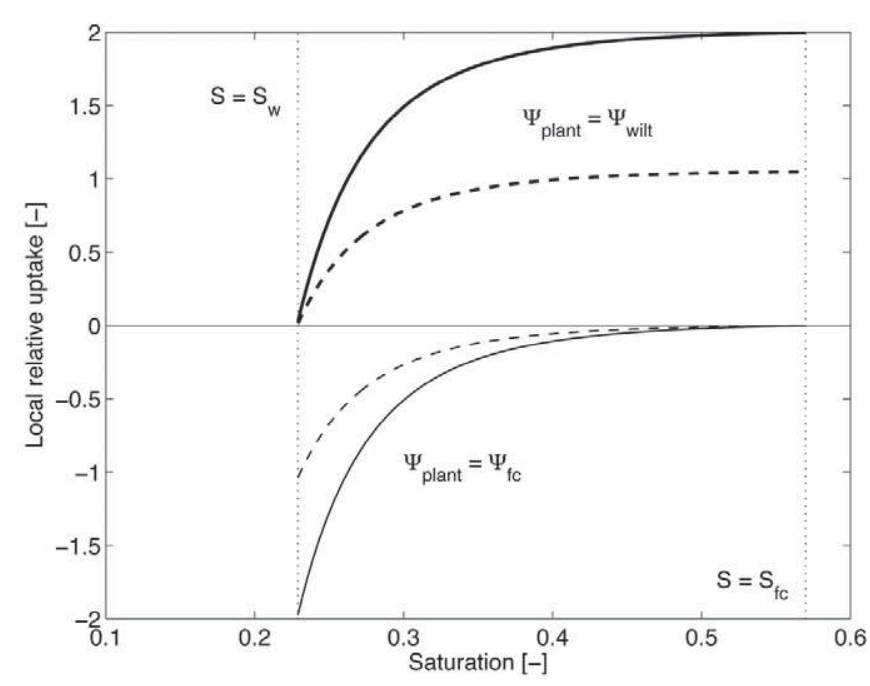

Fig. 1. Local uptake per unit of roots relative to what is needed to meet potential transpiration as a function of water saturation $S$ in the soil. The heavy lines with positive values represent uptake when the plant potential $\Psi_{\text {plant }}$ is equal to the wilting potential $\Psi_{\text {wilt }}$; the lighter curves below zero indicate redistribution of water to the soil when the plant potential is equal to the soil-water potential at field capacity $\left(\Psi_{\mathrm{fc}}\right)$. Dashed lines are the curves for cases with compensation parameter $\gamma$ $=1.05$ and solid lines represent $\gamma=2$. The vertical dotted line is the lower limit on saturation, i.e., the wilting point $\left(S_{\mathrm{w}}\right)$.

bounding behaviors for the root system. It should be emphasized that both root compensation and hydraulic redistribution are not added to the model but come naturally from the Ohm's law formulation of the hydraulic process (e.g., Mendel et al., 2002).

To illustrate the uptake behavior, Fig. 1 presents relative local uptake and hydraulic redistribution as a function of local saturation. The $y$ axis presents the local rate of uptake or redistribution per unit of roots relative to what is required to reach $T_{\text {pot }}$. Curves are presented for two values of plant compensation $(\gamma=1.05$ and 2). The heavy lines represent uptake when the plant potential is equal to the wilting potential, i.e., when the plant is withdrawing water at the maximum rate. When soil water is plentiful (i.e., when saturation is near field capacity), relative local uptake approaches $\gamma(\mathrm{Eq} .[7])$. The strong nonlinearity in the function indicates that local uptake is relatively insensitive to changes in saturation when saturation is high but quite sensitive as the soil dries out.

The lighter lines represent redistribution of water to the soil when the plant potential is equal to $\Psi\left(S_{\mathrm{fc}}\right)$ - that is, when the plant potential is equal to the water potential at field capacity. Such a situation represents a limiting behavior, approached if most of the root zone were wetted to field capacity with only a small fraction of dry roots. Because redistribution occurs in dry soils, the rate of redistribution depends on both the root and soil resistances. In Fig. 1, and throughout this study, the soil resistance was chosen to be small such that the root resistance dominates. In other words,
Table 1. Parameter values used in the model to demonstrate the effects of throughfall variability and root uptake.

\begin{tabular}{|c|c|c|}
\hline Characteristic & Variable & Value \\
\hline Throughfall variability & $\mathrm{CV}$ & $0,0.25$ \\
\hline Root compensation & $\gamma$ & $1.05,2.00$ \\
\hline Hydraulic redistribution & HR & yes, no \\
\hline Interception, $\mathrm{mm}$ event ${ }^{-1}$ & $\Delta$ & 2.5 \\
\hline Soil texture & & $\begin{array}{c}\text { sandy loam (Clapp and } \\
\text { Hornberger, 1978) }\end{array}$ \\
\hline Air-entry pressure, $\mathrm{cm}$ & $\psi_{\mathrm{e}}$ & -22 \\
\hline Hygroscopic saturation & $S_{\mathrm{h}}$ & 0.001 \\
\hline Shape parameter & $b$ & 4.9 \\
\hline Plant-available water & $\begin{array}{l}\theta_{\mathrm{paw}}= \\
\quad n\left(S_{\mathrm{fc}}-S_{\mathrm{w}}\right) \dagger\end{array}$ & 0.14 \\
\hline Maximum root depth, $\mathrm{cm}$ & $Z_{\mathrm{r}}$ & 100 \\
\hline Root distribution, $\mathrm{cm}$ & $Z_{\text {scale }}$ & 30 \\
\hline $\begin{array}{l}\text { Potential transpiration, } \\
\mathrm{mm} \mathrm{d}^{-1}\end{array}$ & $T_{\text {pot }}$ & 3.5 \\
\hline \multirow[t]{2}{*}{$\begin{array}{l}\text { Precipitation: } \\
\text { mean depth, mm; } \\
\text { frequency, } \mathrm{d}^{-1}\end{array}$} & $\alpha ; \lambda^{*}$ & $\begin{array}{l}\alpha=20 ; \lambda^{*}=0.1 \text { (base case) } \\
\alpha=20 ; \lambda^{*}=0.2(\text { wet case) }\end{array}$ \\
\hline & & $\alpha=10 ; \lambda^{*}=0.2$ (light case) \\
\hline
\end{tabular}

$\dagger n$, porosity; $S_{\mathrm{fc}}$, saturation at field capacity; $S_{\mathrm{w}}$, saturation at the wilting point.

this study presumed that the unsaturated hydraulic conductivity at the wilting point is not the factor limiting the efflux or uptake of water. This maximizes the potential for hydraulic redistribution; as seen in Fig. 1, the local, relative rate of uptake (positive) or efflux (negative) is given by

$u(z, t)=\operatorname{RLD}(z) \frac{\Psi[S(z, t)]-\Psi_{\mathrm{p}}}{R_{\mathrm{r}}}$

\section{Scenarios Investigated}

To investigate the competing effects of throughfall variability and root uptake, this study considered a set of core simulations that included two levels of throughfall variability (CV = 0 and 25\%), two levels of root compensation ( $\gamma=1.05$ and 2), and hydraulic redistribution turned on and off. Across these simulations, the interception depth, potential transpiration, plant-available water, and root depth and distribution were held constant. Table 1 indicates the particular values of the parameters used in these simulations. The choice of $Z_{\mathrm{r}}=100 \mathrm{~cm}$ and $Z_{\text {scale }}=30 \mathrm{~cm}$ leads to a root distribution with half of the roots in the top $20 \mathrm{~cm}$ and threequarters in the top $40 \mathrm{~cm}$ (cf., Jackson et al., 1996).

Three different climates were considered: a base case, a light case, and a wet case. In the base case, the mean event depth, $\alpha$, was 20 $\mathrm{mm}$ event $\mathrm{t}^{-1}$ and precipitation frequency was 0.1 events $\mathrm{d}^{-1}$. The climate of this base case can be characterized by two important 
dimensionless parameters. The first is the ratio of mean precipitation to potential transpiration, $W=\alpha \lambda^{*} / T_{\text {pot }}$ (e.g., United Nations Environment Programme, 1997; Milly, 1993). The second is a normalized root depth

$Z^{*}=\frac{\theta_{\text {paw }} Z_{\text {scale }}}{\alpha}$

where $\theta_{\text {paw }}$ is the plant-available water content (i.e., the difference between water content at field capacity and the wilting point) and $Z^{*}$ represents the number of mean throughfall events that can be absorbed by a dry soil within the depth $Z_{\text {scale }}$. For the base climate, $W$ was 0.57 , indicating a dry climate, and $Z^{*}$ was 2.1 . In addition to this base case, this work also considered a light case $(\alpha=10 \mathrm{~mm}$ event $^{-1}, \lambda^{*}=0.2$ events $\left.\mathrm{d}^{-1}\right)$, for which $W$ remained at 0.57 but $Z^{*}$ $=4.2$, and a wet case $\left(\alpha=20 \mathrm{~mm} \mathrm{event}^{-1}, \lambda^{*}=0.2\right.$ events $\left.^{-1}\right)$, for which $W=1.14$ and $Z^{*}$ was 2.1 .

For the scenarios with spatially varying throughfall, simulations were run for $10,000 \mathrm{~d}$ for 100 coupled one-dimensional models, each with 50 soil layers. For the homogenous cases, a single onedimensional model with 50 layers was used. Across these scenarios, the combined effects of canopy and root processes were investigated with respect to the water balance, the localization of recharge, the spatial and temporal variability of soil moisture, and the upscaled relationship between stand-average soil moisture and transpiration.

\section{Results}

The intent of this modeling effort was twofold. First, this study sought to explore the fundamental interplay between the spatial variability generated by canopy processes and the homogenizing effects of root processes. Additionally, this study sought to provide insight into the pragmatic question of what errors are introduced if the spatial effects of both canopy and root processes are neglected. That is, what differences result from representing the system as homogenous in horizontal space at the patch scale (as many hydrologic models do) vs. accounting for horizontal variability?

\section{Water Balance}

The effect of canopy and root processes on the water balance, specifically the ratio of recharge to infiltration, is presented in Table 2 for the base and wet climates. Under the light climate, recharge was effectively zero for all cases. For the base climate, spatially varying throughfall resulted in an increase in recharge; for the wet climate, the effect of throughfall variability on the water balance was small or negligible. Hydraulic redistribution and increased root compensation both had the effect of reducing recharge (and, concomitantly, increasing transpiration). For the wetter climate, hydraulic redistribution had a more modest effect on the recharge ratio than when the climate was drier. Relative to hydraulic redistribution
(HR), root compensation had a larger effect on the water balance. Comparing the case of a homogenous input of water and limited root processes $(\mathrm{CV}=0, \gamma=1.05, \mathrm{HR}=$ false $)$ with the case of heterogeneous throughfall and active roots $(\mathrm{CV}=25 \%, \gamma=2, \mathrm{HR}$ $=$ true), Table 2 indicates that the water balance was similar under the base climate: recharge ratios of 0.023 vs. 0.027 , respectively. For the wet climate, the incorporation of root processes reduced recharge by nearly one-third below what was calculated when horizontal variability was neglected.

\section{Recharge Concentration}

In addition to influencing the mean patch-scale water balance and recharge, canopy and root processes can affect the localization of recharge. Redistribution of throughfall into persistent wet and dry spots concentrates recharge; this effect increased with increasing CV of throughfall (Guswa and Spence, 2012). Figure 2 presents the

Table 2. Recharge ratio (average recharge/average infiltration) for base and wet climates and homogenous $(\mathrm{CV}=0)$ and spatially variable $(\mathrm{CV}$ $=25 \%)$ throughfall.

\begin{tabular}{l|lll|l|l} 
& & \multicolumn{3}{|l}{ Recharge ratio } \\
\cline { 3 - 6 } $\begin{array}{l}\text { Root } \\
\text { compensation }\end{array}$ & $\begin{array}{l}\text { Hydraulic } \\
\text { Redistribution }\end{array}$ & \multicolumn{2}{l}{ Base climate } & \multicolumn{2}{l}{ Wet climate } \\
\hline 1.05 & no & 0.023 & 0.052 & 0.16 & 0.17 \\
1.05 & yes & 0.017 & 0.040 & 0.15 & 0.17 \\
2.0 & no & 0.020 & 0.024 & 0.11 & 0.14 \\
2.0 & yes & 0.008 & 0.027 & 0.12 & 0.11 \\
\hline
\end{tabular}

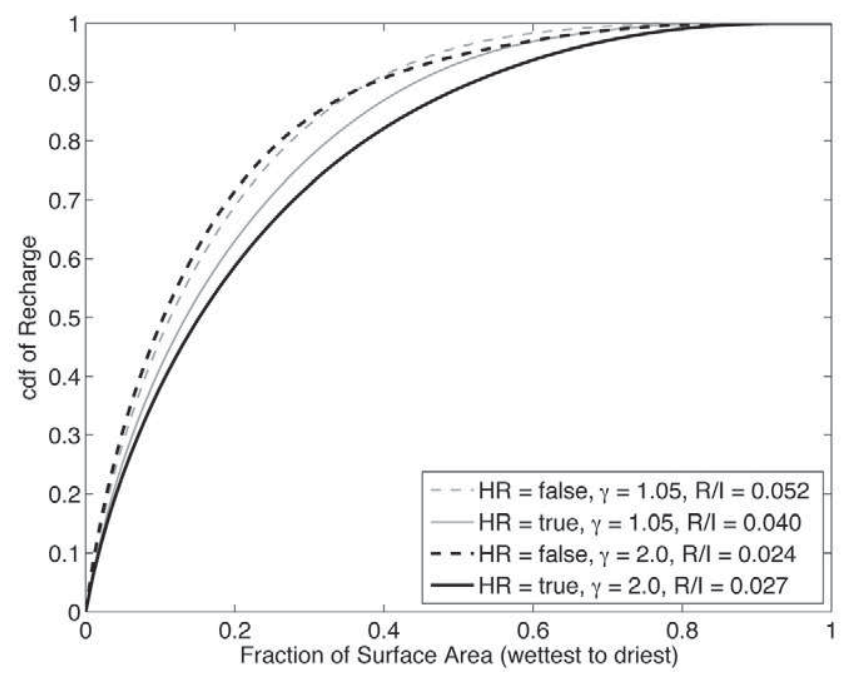

Fig. 2. Localization of recharge under the base climate scenarios presented as the spatial cumulative distribution function for recharge. Solid lines represent cases for which nighttime hydraulic redistribution occurs $(\mathrm{HR}=$ true $)$, and dashed lines represent cases without hydraulic redistribution ( $\mathrm{HR}=$ false); $\gamma$ represents the degree of root compensation (Eq. [7]), and the heavier black lines indicate cases with a high degree of root compensation $(\gamma=2)$. 
effect of root processes on this localization for the base climate. The figure presents the spatial cumulative distribution function (cdf) of recharge, moving from the wettest portion of the forest floor to the driest. For a homogenous input of water, the curve would follow the 1:1 line. When throughfall varies in space, hydraulic redistribution and increased root compensation have only a moderate effect on undoing the recharge concentration generated by canopy processes. For all four cases, approximately $90 \%$ of total recharge was generated in just half of the domain. Hydraulic redistribution (solid lines) had a slightly larger effect than increased root compensation (black lines), leading to cdfs that were slightly more linear than in the case of no hydraulic redistribution. Curves for the wet case (not shown) also showed this localization effect and were even less differentiated by root processes than those in Fig. 2. When comparing among the cdfs, it is important to keep in mind that the total amount of recharge varied among the scenarios, as expressed by the recharge/infiltration ratio.

\section{Spatial Variability of Soil Moisture}

Similar to the recharge concentration, canopy and root processes also affect the horizontal variability of soil moisture within a patch. The horizontal variability of infiltration generated by canopy processes leads to variability in soil moisture, modulated by averaging depth. In this study, two averaging depths were considered: 40 and $100 \mathrm{~cm}$, which correspond to the top 75 and $100 \%$ of the plant roots, respectively. The variables $S 40$ and $S 100$ represent the vertically averaged saturations within these depths. These quantities were calculated at the start of each day, as were measures of their horizontal variability: $\sigma_{x, S 40}$ and $\sigma_{x, S 100}$, representing the spatial standard deviation of vertically averaged saturation. Horizontally averaged values of $S 40$ and $S 100$, i.e., daily values of mean soil moisture within the patch, are indicated by $S 40_{\mathrm{avg}}$ and $S 100_{\mathrm{avg}}$. Temporal averages $\left(\left\langle S 40_{\mathrm{avg}}\right\rangle\right.$, $\left\langle S 100_{\text {avg }}\right\rangle,\left\langle\sigma_{x, S 40}\right\rangle$, and $\left.\left\langle\sigma_{x, S 100^{\prime}}\right\rangle\right)$ indicate characteristic values across the entire simulation, and Tables 3,4 , and 5 present results for the base, wet, and light climates, respectively.

For the base case, long-term averages of soil moisture, $\left\langle S 40_{\text {avg }}\right\rangle$ and $\left\langle\mathrm{S}_{100} \mathrm{avg}_{\mathrm{a}}\right\rangle$, were relatively unaffected by root processes,

Table 3. Effect of throughfall variability and root processes on the recharge ratio and soil-moisture variability for the base case. For these simulations, precipitation frequency was 0.1 events $\mathrm{d}^{-1}$ and mean depth was $20 \mathrm{~mm}_{\text {event }}{ }^{-1}$. The combinations of these values correspond to values of climate wetness of 0.57 and normalized root depth of 2.1. The variables $\left\langle\mathrm{S} 40_{\text {avg }}>\right.$ and $\left\langle\mathrm{S} 100_{\text {avg }}>\right.$ represent the long-term averages of soil moisture in the top 40 and $100 \mathrm{~cm}$ of the root zone, respectively, and $\left\langle\sigma_{x, S 40}>\right.$ and $\left\langle\sigma_{x, S 100}>\right.$ represent the long-term averages of the spatial standard deviation of daily soil moisture in the top 40 and $100 \mathrm{~cm}$ of the root zone, respectively.

\begin{tabular}{|c|c|c|c|c|c|c|c|c|}
\hline \multirow{2}{*}{$\begin{array}{l}\text { Throughfall } \\
\text { variability }\end{array}$} & \multirow{2}{*}{$\begin{array}{l}\text { Root } \\
\text { compensation }\end{array}$} & \multicolumn{2}{|c|}{ Hydraulic redistribution } & \multirow[b]{2}{*}{ Recharge ratio $\dagger$} & \multicolumn{2}{|l|}{ Top $40 \mathrm{~cm}$} & \multicolumn{2}{|l|}{ Top $100 \mathrm{~cm}$} \\
\hline & & Occurrence & Rate & & $<\mathrm{S} 40_{\mathrm{avg}}>$ & $<\sigma_{x, S 40}>$ & $<S 100_{\text {avg }}>$ & $<\sigma_{x, S 100}>$ \\
\hline$\%$ & & & $\mathrm{~mm} \mathrm{~d}^{-1}$ & & & & & \\
\hline 0 & 1.05 & no & - & 0.023 & 0.33 & - & 0.31 & - \\
\hline 25 & 1.05 & no & - & 0.052 & 0.33 & 0.019 & 0.32 & 0.040 \\
\hline 25 & 1.05 & yes & 0.32 & 0.040 & 0.33 & 0.016 & 0.31 & 0.025 \\
\hline 25 & 2.0 & no & - & 0.024 & 0.31 & 0.015 & 0.28 & 0.023 \\
\hline 25 & 2.0 & yes & 0.42 & 0.027 & 0.30 & 0.010 & 0.28 & 0.014 \\
\hline
\end{tabular}

† Average recharge/average infiltration.

Table 4. Effect of throughfall variability and root processes on recharge ratio and soil-moisture variability for the wet case. For these simulations, precipitation frequency was 0.2 events $\mathrm{d}^{-1}$ and mean depth was $20 \mathrm{~mm}_{\text {event }}{ }^{-1}$. The combinations of these values correspond to values of climate wetness of 1.14 and normalized root depth of 2.1. The variables $<S 40_{\text {avg }}>$ and $<S 100_{\text {avg }}>$ represent the long-term averages of soil moisture in the top 40 and $100 \mathrm{~cm}$ of the root zone, respectively, and $\left\langle\sigma_{x, S 40}\right\rangle$ and $\left\langle\sigma_{x, S 100}>\right.$ represent the long-term averages of the spatial standard deviation of daily soil moisture in the top 40 and $100 \mathrm{~cm}$ of the root zone, respectively.

\begin{tabular}{|c|c|c|c|c|c|c|c|c|}
\hline \multirow{2}{*}{$\begin{array}{l}\text { Throughfall } \\
\text { variability }\end{array}$} & \multirow{2}{*}{$\begin{array}{l}\text { Root } \\
\text { compensation }\end{array}$} & \multicolumn{2}{|c|}{ Hydraulic redistribution } & \multirow[b]{2}{*}{ Recharge ratio $\dagger$} & \multicolumn{2}{|l|}{ Top $40 \mathrm{~cm}$} & \multicolumn{2}{|l|}{ Top $100 \mathrm{~cm}$} \\
\hline & & Occurrence & Rate & & $<\mathrm{S} 40_{\text {avg }}>$ & $<\sigma_{x, S 40}>$ & $<S 100_{\text {avg }}>$ & $<\sigma_{x, S 100}>$ \\
\hline$\%$ & & & $\mathrm{~mm} \mathrm{~d}^{-1}$ & & & & & \\
\hline 0 & 1.05 & no & - & 0.16 & 0.42 & - & 0.43 & - \\
\hline 25 & 1.05 & no & - & 0.17 & 0.42 & 0.025 & 0.42 & 0.051 \\
\hline 25 & 1.05 & yes & 0.27 & 0.17 & 0.41 & 0.020 & 0.41 & 0.038 \\
\hline 25 & 2.0 & no & - & 0.14 & 0.39 & 0.020 & 0.38 & 0.040 \\
\hline 25 & 2.0 & yes & 0.44 & 0.11 & 0.38 & 0.016 & 0.37 & 0.031 \\
\hline
\end{tabular}

† Average recharge/average infiltration. 
Table 5. Effect of throughfall variability and root processes on recharge ratio and soil moisture variability for the light case. For these simulations, precipitation frequency is 0.2 events $\mathrm{d}^{-1}$ and mean depth is $10 \mathrm{~mm}_{\text {event }}^{-1}$. The combinations of these values correspond to values of climate wetness of 0.57 and normalized root depth of 4.2 . The variables $\left\langle\mathrm{S} 40_{\text {avg }}\right\rangle$ and $\left\langle\mathrm{S} 100_{\text {avg }}\right\rangle$ represent the long-term averages of soil moisture in the top 40 and 100 $\mathrm{cm}$ of the root zone, respectively, and $\left\langle\sigma_{x, S 40}\right\rangle$ and $\left\langle\sigma_{x, S 100}>\right.$ represent the long-term averages of the spatial standard deviation of daily soil moisture in the top 40 and $100 \mathrm{~cm}$ of the root zone, respectively.

\begin{tabular}{|c|c|c|c|c|c|c|c|c|}
\hline $\begin{array}{l}\text { Throughfall } \\
\text { variability }\end{array}$ & $\begin{array}{l}\text { Root } \\
\text { compensation }\end{array}$ & \multicolumn{2}{|c|}{ Hydraulic redistribution } & Recharge ratio $\dagger$ & \multicolumn{2}{|l|}{ Top $40 \mathrm{~cm}$} & \multicolumn{2}{|l|}{ Top $100 \mathrm{~cm}$} \\
\hline$\%$ & & & $\mathrm{~mm} \mathrm{~d}^{-1}$ & & & & & \\
\hline 0 & 1.05 & no & - & 0.00 & 0.34 & & 0.28 & \\
\hline 25 & 1.05 & no & - & 0.00 & 0.33 & 0.028 & 0.28 & 0.023 \\
\hline 25 & 1.05 & yes & 0.39 & 0.00 & 0.31 & 0.019 & 0.27 & 0.013 \\
\hline 25 & 2.0 & yes & 0.47 & 0.00 & 0.28 & 0.010 & 0.25 & 0.006 \\
\hline
\end{tabular}

† Average recharge/average infiltration.

although root compensation $(\gamma)$ had a modest effect (Table 3). Both root compensation and hydraulic redistribution, however, had a notable effect on the horizontal variability of soil moisture. For the top $40 \mathrm{~cm}$ of the root zone, the long-term average of $\sigma_{x, S 40}$ decreased from 0.019 to 0.010 . Similarly, $<\sigma_{x, S 100}>$ went from 0.040 to 0.014 as roots became more active. Tables 4 and 5 indicate that the results were similar for the wet and light cases; mean soil moisture was slightly affected by root processes, which had a greater effect on soil moisture variability.

Figure 3 presents histograms of daily $\sigma_{x, S 40}$ for the base climate. As evidenced in these plots, most days have low spatial variability, and the frequency of days with larger spatial variability drops off quickly. As roots become more active, the distribution becomes steeper, with a higher fraction of lower variability days and a flatter tail. Figure 4 presents the covariation of $\sigma_{x, S 40}$ and $S 40_{\text {avg }}$. Each point represents a value of $S 40_{\text {avg }}$ and $\sigma_{x, S 40}$ for $1 \mathrm{~d}$, and the dashed lines represent the mean values across the length of the simulation (i.e., $<S 40_{\text {avg }}>$ and $<\sigma_{x, S 40}>$ ). Points are color coded to indicate the corresponding magnitude of daily transpiration, with blue representing transpiration $T>0.9 T_{\text {pot }}$ and red representing days for which $T<0.5 T_{\text {pot }}$. Spatial variability is pinned at zero for $S 40_{\text {avg }}=S_{\mathrm{w}}$ and $S 40_{\text {avg }}=S_{\mathrm{fc}}$ because those saturations are achievable only for a homogenous distribution of soil moisture. Excepting the cases for which the entire patch is uniformly wet, spatial variability is larger when soil moisture is high and decreases as the soil dries out. Increased root activity has the effect of flattening the envelope and reducing spatial variability when the soil was dry. This effect appears more pronounced for the process of hydraulic redistribution than for increased root compensation (compare Fig. $4 \mathrm{~b}$ and $4 \mathrm{~d}$ with Fig. $4 \mathrm{a}$ and $4 \mathrm{c})$. Root compensation had a larger effect on the transpiration rate, however. For a given pairing of mean soil moisture and horizontal variability, i.e., for a similar geometric arrangement of soil moisture, transpiration is greater in Fig. $4 c$ and $4 d$ than in Fig. $4 a$ and $4 b$. (a) $\mathrm{HR}=$ false, $\gamma=1.05$
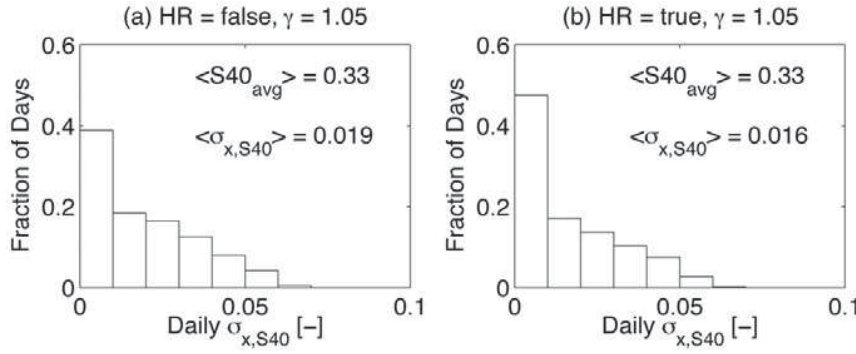

(c) $\mathrm{HR}=$ false, $\gamma=2.0$
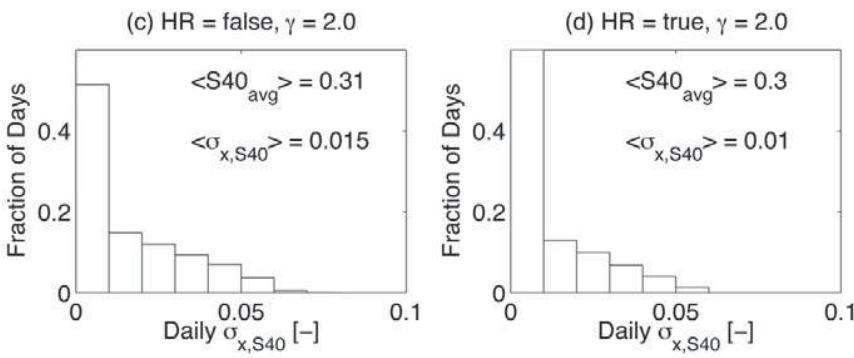

Fig. 3. Histograms of horizontal variability of daily soil moisture in the top $40 \mathrm{~cm}$ for the base climate; HR indicates whether hydraulic redistribution is included (true) or prohibited (false), $\gamma$ represents the degree of root compensation (Eq. [7]), $<\mathrm{S} 40_{\mathrm{avg}}>$ represents the long-term average soil moisture in the top $40 \mathrm{~cm}$ of the root zone, and $\left\langle\sigma_{x, S 40}>\right.$ represents the long-term average of the spatial standard deviation of daily soil moisture in the top $40 \mathrm{~cm}$, i.e., the mean for the histogram.

\section{Temporal Variability of Soil Moisture}

To complement the effects of root processes on the horizontal variability of soil moisture, Fig. 5 presents the temporal variability of $S 40$ and $S 100$ as a function of horizontal location for the base climate. Measures of temporal variability, $\sigma_{t, S 40}$ and $\sigma_{t, S 100}$, were calculated as the temporal standard deviation of $S 40$ or $S 100$, respectively, across the length of the simulation. Horizontal position within the forest patch is characterized by its local value of infiltration relative to the average for the stand, and larger values 
(a) $\mathrm{HR}=$ false, $\gamma=1.05$

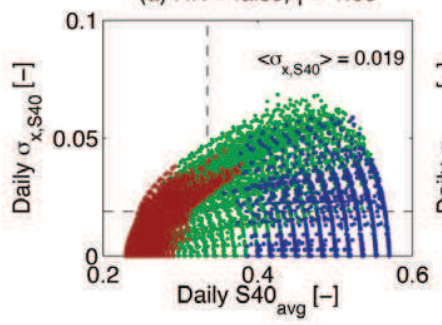

(c) $H R=$ false, $\gamma=2.0$

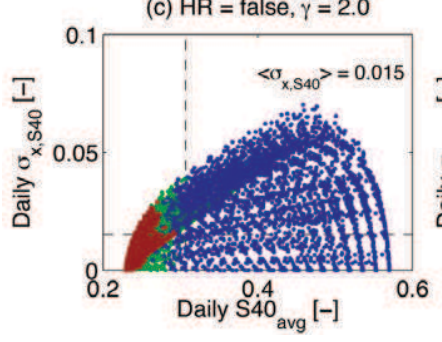

(b) $\mathrm{HR}=$ true, $\gamma=1.05$

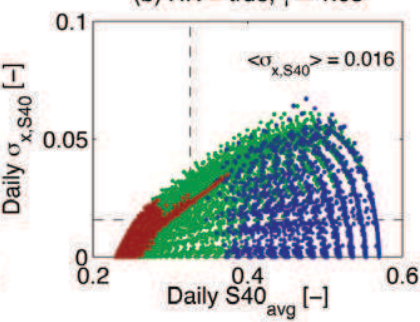

(d) HR = true, $\gamma=2.0$

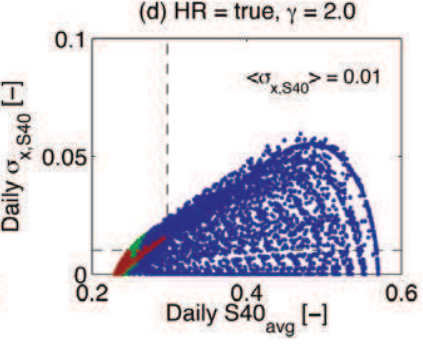

Fig. 4. Daily soil-moisture variability, $\sigma_{x, S 40}$, as a function of daily average soil moisture $S 40_{\text {avg }}$ in the top $40 \mathrm{~cm}$ of soil for the base climate. Blue points indicate days for which transpiration was $>90 \%$ of potential transpiration $T_{\text {pot }}$, while red points represent days for which transpiration was $<50 \%$ of $T_{\text {pot }}$; HR indicates whether hydraulic redistribution is included (true) or prohibited (false), and $\gamma$ represents the degree of root compensation (Eq. [7]). The horizontal dashed line indicates the value of $\left\langle\sigma_{x, S 40}\right\rangle$, the long-term average of the spatial standard deviation of daily soil moisture in the top $40 \mathrm{~cm}$; the vertical dashed line represents the long-term average soil moisture in the top $40 \mathrm{~cm}$ of the root zone, i.e., $\left.<\mathrm{S} 40_{\mathrm{avg}}\right\rangle$.

indicate wetter spots. Dashed horizontal lines indicate the temporal variability of S 40 and $S 100$ for scenarios with homogenous throughfall, i.e., with the patch represented with a single onedimensional model.

All plots for the base climate (Fig. 5) indicate that the temporal variability of vertically averaged soil moisture generally increased with increasing wetness; drier spots were consistently dry, while wetter spots experienced wetting and drying cycles. Root activity acted to reduce the overall temporal variability (slightly, as indicated in the legend by changes to the averages of $\sigma_{t, S 40}$ and $\sigma_{t, S 100}$ within the patch), but the local effects varied with relative wetness. With increasing root activity (hydraulic redistribution or increased root compensation), wet spots see a slight increase in temporal variability, and the center portions of the distributions are pushed down, leading to more linear curves moving from Fig. $5 \mathrm{a}$ to $5 \mathrm{~d}$.

In contrast, Fig. 6 presents the same figure for the wet climate. In this case, root activity tended to increase the overall temporal variability of soil moisture for the patch, and, again, local effects were dependent on the wetness of the location. The temporal variability of dry regions was relatively unaffected, while wetter regions saw an increase in temporal variability as roots acted to deplete those regions more quickly. Also, relative to Fig. 5, many of the curves in

(a) $\mathrm{HR}=$ false, $\gamma=1.05$

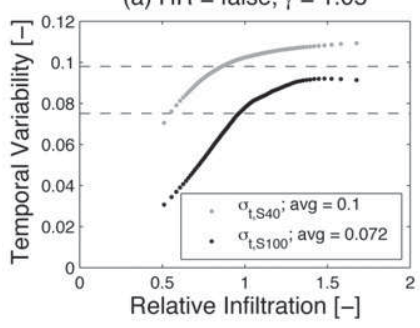

(c) $\mathrm{HR}=$ false, $\gamma=2.0$

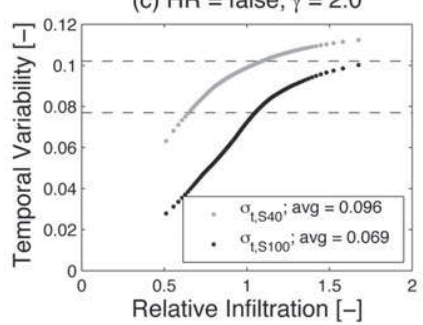

(b) $\mathrm{HR}=$ true, $\gamma=1.05$

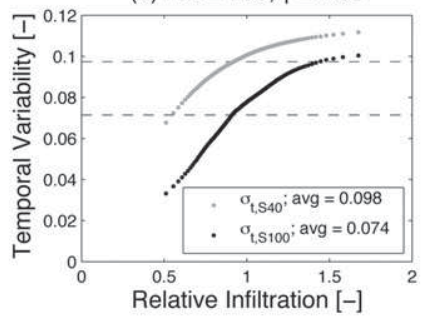

(d) HR = true, $\gamma=2.0$

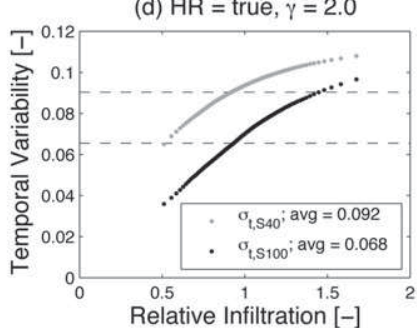

Fig. 5. Temporal variability of soil moisture $\left(\sigma_{t}\right)$ as a function of wetness for the base climate. Relative infiltration is the ratio of local infiltration to stand-mean infiltration. The horizontal dashed lines indicate the temporal variability of saturation in the upper $40 \mathrm{~cm}$ (S40, upper line) and the upper $100 \mathrm{~cm}$ (S100, lower line) for the case of spatially uniform throughfall; HR indicates whether hydraulic redistribution is included (true) or prohibited (false), and $\gamma$ represents the degree of root compensation (Eq. [7]).

(a) $\mathrm{HR}=$ false, $\gamma=1.05$

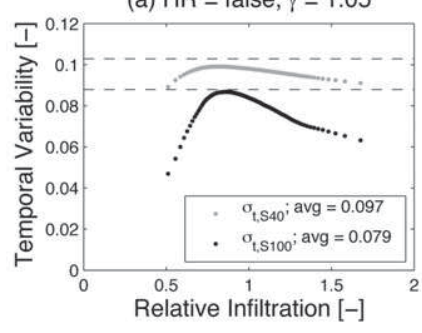

(c) $\mathrm{HR}=$ false, $\gamma=2.0$

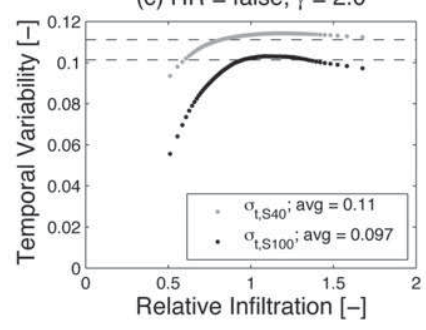

(b) $\mathrm{HR}=$ true, $\gamma=1.05$

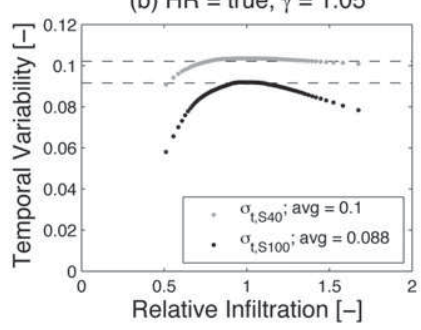

(d) $\mathrm{HR}=$ true, $\gamma=2.0$

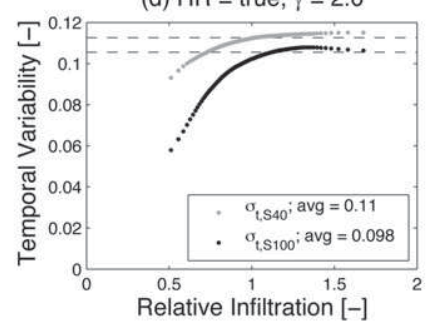

Fig. 6. Temporal variability of soil moisture $\left(\sigma_{t}\right)$ as a function of wetness for the wet climate. Relative infiltration is the ratio of local infiltration to stand-mean infiltration. The horizontal dashed lines indicate the temporal variability of saturation in the upper $40 \mathrm{~cm}$ (S40, upper line) and the upper $100 \mathrm{~cm}$ (S100, lower line) for the case of spatially uniform throughfall; HR indicates whether hydraulic redistribution is included (true) or prohibited (false), and $\gamma$ represents the degree of root compensation (Eq. [7]). 
(a) $\mathrm{HR}=$ false, $\gamma=1.05$

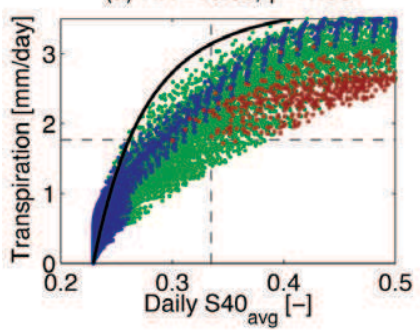

(c) $\mathrm{HR}=$ false, $\gamma=2.0$
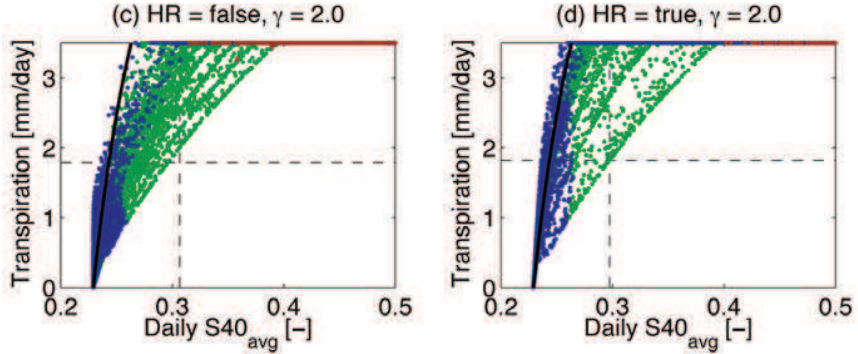

Fig. 7. Upscaled relationship between stand-mean soil moisture in the top $40 \mathrm{~cm}$ (daily $S 40_{\text {avg }}$ ) and daily transpiration for the base climate and spatially varying throughfall. The heavy solid line indicates the relationship for a homogenous distribution of soil moisture. Blue points indicate days for which the spatial coefficient of variation for soil moisture in the top $40 \mathrm{~cm}$ (i.e., $\sigma_{x, S 40} / S 40$ avg ) is less than 0.03 , and red points represent days for which it is greater than 0.15 . The light dashed lines indicate long-term averages; HR indicates whether hydraulic redistribution is included (true) or prohibited (false), and $\gamma$ represents the degree of root compensation (Eq. [7]).

Fig. 6 are not monotonic but exhibit local maxima for intermediate values of infiltration. With a wetness index, $W$, near 1 , average precipitation and evapotranspiration were approximately in balance for this climate. Thus, for intermediate values of infiltration, the wetting and drying cycles led to significant temporal variability. Wetter spots, with increased relative infiltration, produced soils that were more consistently wet with lower temporal variability, and a similar effect is seen for the dry spots.

\section{Upscaled Transpiration}

Figure 7 presents the upscaled relationship between average daily transpiration and $S 40_{\text {avg }}$. Each point represents a daily value of transpiration averaged across the forest patch and the corresponding value of $S 40_{\mathrm{avg}}$ at the start of the day. The nonunique cloud of points relating $S 40$ avg and daily transpiration arose due to the dependence of plant uptake on not only the mean value of soil moisture but also its geometric arrangement across the root zone. Each point is color coded according to horizontal variability. Blue points indicate days for which soil moisture was relatively homogenous: $\sigma_{x, S 40} / S 40$ avg is $<0.03$; red points indicate days for which soil moisture was more variable: $\sigma_{x, S 40} / \mathrm{S} 40_{\text {avg }}$ is $>0.15$. The dashed lines indicate temporally averaged values of transpiration and $S 40_{\text {avg }}$ throughout the entire length of the simulation. The solid black line indicates what the uptake would be if soil moisture were spatially homogenous (a) $\mathrm{HR}=$ false, $\gamma=1.05$

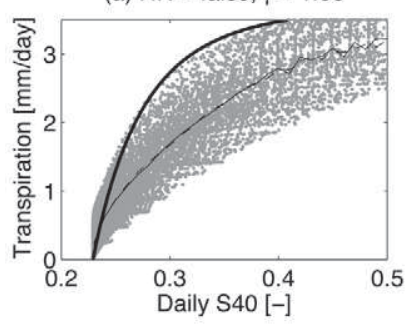

(c) $\mathrm{HR}=$ false, $\gamma=2.0$

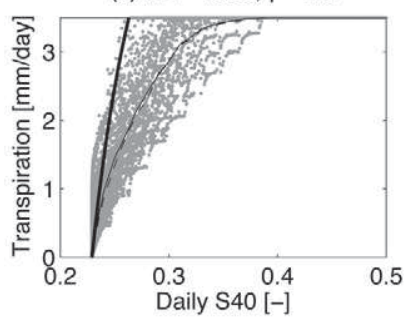

(b) $\mathrm{HR}=$ true, $\gamma=1.05$

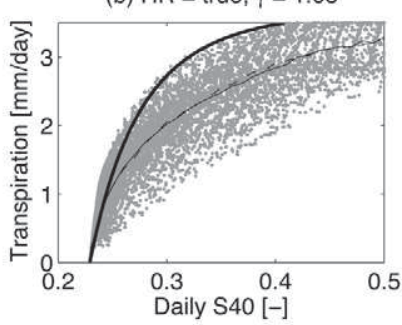

(d) HR = true, $\gamma=2.0$

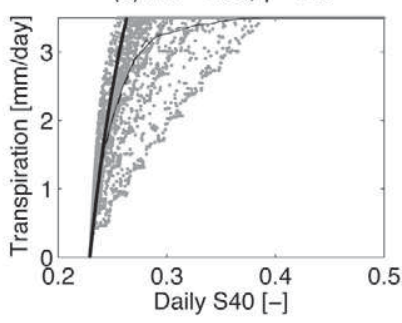

Fig. 8. Upscaled relationship between soil moisture in the top $40 \mathrm{~cm}$ (daily S40) and daily transpiration for the base climate and uniform throughfall. The heavy solid line indicates the relationship for a homogenous distribution of soil moisture. The light solid and dashed lines (nearly overlapping) represent average transpiration across the cloud of points for given values of S40 for cases with homogenous and spatially varying throughfall, respectfully; HR indicates whether hydraulic redistribution is included (true) or prohibited (false), and $\gamma$ represents the degree of root compensation (Eq. [7]).

(horizontally and vertically). Note that some of the upscaled points lie above this envelope (see the points corresponding to low saturations) because the plant roots were not uniformly distributed. For example, even if most of the root zone is dry, a light rain that wets the top soil layers, where most of the roots are, can lead to significant plant uptake.

As indicated in Fig. 7, the upscaled relationship between $S 40_{\text {avg }}$ and transpiration is strongly dependent on the value of root compensation, $\gamma$. Additionally, hydraulic redistribution has the effect of reducing the spread of points and pushing them closer to the relationship for homogenous soil moisture. To fully understand Fig. 7, however, it is useful to know whether the nonuniqueness in the relationship between daily transpiration and $S 40_{\text {avg }}$ is due primarily to horizontal or vertical variability in soil moisture. Therefore, Fig. 8 presents the same results as Fig. 7 but for homogenous throughfall; i.e., the only soil moisture variability is in the vertical direction. The similarity between Fig. 7 and 8 indicates that much of the nonuniqueness in the relationship between transpiration and average root zone saturation is due to the vertical distribution of soil moisture (cf., Guswa et al., 2002, 2004; Guswa, 2005).

\section{Discussion}

The model results of this study elucidate the competing effects of canopy interception and root uptake on the spatial and temporal 
variability of soil moisture and associated hydrologic fluxes. The focus was on a homogenous vegetation patch with little or no topographic relief. Spatial variability introduced by throughfall was represented as perfectly persistent and of a magnitude consistent with multiple field studies (e.g., Guswa and Spence, 2012; Keim et al., 2005; Carlyle-Moses et al., 2004; Raat et al., 2002; Loustau et al., 1992). Root uptake was represented with a familiar electric circuit analogy (e.g., Gardner, 1960; Cowan, 1965), which included the effects of root compensation and hydraulic redistribution. Each of these root processes was considered with two levels, representing ends of the spectrum, i.e., root systems with little ability to compensate for spatial variations in soil moisture and those at the upper end of what has been observed in the field.

For the base climate, with a low ratio of recharge to infiltration, throughfall variability increased recharge and decreased transpiration (Table 2). This is consistent with the findings of Guswa and Spence (2012), which were based on point models of soil-moisture dynamics without an explicit representation of root compensation and hydraulic redistribution. That work demonstrated that recharge increases with increasing $\mathrm{CV}$ of throughfall and that the effects are greater for deeper roots and drier climates. The results of this study indicate that increasing root activity has the potential to reduce or eliminate the effects of throughfall variability on the patch-scale water balance (Table 2). Specifically, under the base climate, the recharge ratio for independent roots $(\gamma=1.05$, HR $=$ false) and homogenous throughfall was approximately equal to that for variable throughfall and active roots $(\gamma=2)$. For a wetter climate, however, the impact of throughfall variability was diminished, and increased root activity may lead to lower rates of recharge even when throughfall variability is increased. Therefore, in some instances, the horizontal processes at the patch scale (canopy redistribution and root activity) may be offsetting, and their neglect may not affect water-balance predictions. In other cases, one of the processes may dominate, and a failure to represent the effects may lead to errors in the water balance.

Regardless of the net effect on the patch-scale water balance, the scenarios investigated here indicate that heterogeneous throughfall will always lead to a localization of recharge (Fig. 2). Even high levels of root activity $(\gamma=2, \mathrm{HR}=$ true $)$ are insufficient to counter the concentrating effects of canopy redistribution. This result may in part explain recent findings regarding the ecohydrologic separation of water that supplies stream flow from water that supplies transpiration (e.g., Brooks et al., 2010; Phillips, 2010). In combination with macropore flow and water held tightly in small pores (Brooks et al., 2010), redistribution of throughfall by forest canopies could lead to significant portions of the forest patch that generate little or no recharge and are depleted by plant uptake only and a few locations of concentrated recharge that rapidly transmit water below the root zone.
Additionally, this localization of recharge can impact biogeochemical processes, nutrient cycling, mineral weathering, and solute leaching. Similarly, spatial variability of saturation at the patch scale will affect those processes that are nonlinear functions of soil moisture. This result is consistent with the framework of hot spots and hot moments (Vidon et al., 2010; McClain et al., 2003), which indicates that average biogeochemical rates and fluxes can be dominated by interactions at small spatial and temporal scales. Thus, failure to account for the spatial concentration of water in biogeochemical process and transport models may lead to erroneous results. Root activity has the potential to reduce but not eliminate the horizontal variability of soil moisture and fluxes (Tables 3-5; Fig. 2, 3, and 4).

Effects on the temporal variability of root-zone soil moisture are more complex. For the base climate (Fig. 5), canopy redistribution led to dry spots with lower temporal variability and wetter spots with higher variability than the homogenous case (compare the points to the dashed lines in Fig. 5). Increased root activity had only a minor effect on the temporal variability of soil moisture under the base climate. For the wet climate, the temporal variability of rootzone soil moisture was spatially more uniform and slightly greater than for the base climate. From the drier to the wetter spots, the temporal variability of $S 40$ was similar and close to the value for the case of homogenous throughfall. Under the wet climate, increased root activity increased the temporal variability of wetter spots and decreased the variability of drier spots. As with spatial variability, these effects can impact ecohydrologic processes that are nonlinear functions of soil moisture. For example, with high rates of root activity, dry spots may be maintained in a slightly wetter state and may be more hospitable to microorganisms. Wet spots will dry more quickly, perhaps leading to increased aeration of the soil.

Figures 7 and 8 indicate that the upscaled relationship between patch-scale soil moisture and daily transpiration is complex and nonunique. Most of the nonuniqueness in the relationship stems from vertical rather than horizontal variability in soil moisture (cf., Guswa et al., 2004; Guswa, 2005). Therefore, a vertically layered model that homogenizes in the horizontal direction may be adequate to represent the upscaled relationship.

All of these implications are predicated on model results, and a discussion of some key simplifications is warranted. One simplification is that throughfall is perfectly persistent in time; that is, the wetness rank of an individual soil column was fixed. While this is consistent with general patterns observed in field studies, it represents an extreme. Measured data also showed event-to-event variability in throughfall rank, driven in part by abiotic factors such as rainfall intensity and wind speed and direction. The overall magnitude of the spatial coefficients of variation used in this work incorporated these effects because the coefficients match the data from longer term accumulations. Nonetheless, the event-to-event variability of throughfall in the field will be larger than what is represented here and will affect the temporal and spatial variability of soil moisture. 
This work also eliminated the soil resistance term from the uptake function (Eq. [8]). Therefore, hydraulic redistribution was higher than what it would be if represented with Eq. [4]. Given that exudation of water from plant roots is a very local phenomenon, it is unclear that an unsaturated hydraulic conductivity calculated as a function of average saturation would be appropriate to represent the soil resistance for this process. Thus, there is more work to be done with respect to upscaling the movement of soil water not only to roots following infiltration but also from and to plant roots via hydraulic redistribution.

\section{Conclusions}

A set of numerical experiments were used to investigate the competing effects of canopy and root processes at the patch scale on the water balance, recharge localization, spatial and temporal variability of soil moisture, and the upscaled relationship between mean soil moisture and transpiration. The water balance and upscaled fluxes were somewhat insensitive to horizontal variability, although there may be some conditions for which the effects are large. The homogenizing effects of root uptake can also undo some of the effects that result from canopy processes. Thus, failure to account for horizontal variability may not have a large effect on the water balance. In contrast, canopy interception had a noticeable effect on recharge localization and the horizontal variability of soil moisture. Thus, these processes may need to be accounted for to properly represent biogeochemical processes that are nonlinear functions of soil moisture, and this may also help explain the phenomenon of soil-water bypass (Brooks et al., 2010). In all cases, the particular results depend on the strength of the canopy and root processes, along with the characteristics of climate, soil, and vegetation.

\section{References}

Auge, R.M., A.J.W. Stodola, R.C. Ebel, and X. Duan. 1995. Leaf elongation and water relations of mycorrhizal sorghum in response to partial soil drying: Two Glomus species at varying phosphorous fertilization. J. Exp. Bot. 46:297-307. doi:10.1093/jxb/46.3.297

Bouten, W., T.J. Heimovaara, and A. Tiktak. 1992. Spatial patterns of throughfall and soil water dynamics in a Douglas fir stand. Water Resour. Res. 28:32273233. doi:10.1029/92WR01764

Breazeale, J.F. 1930. Maintenance of moisture-equilibrium and nutrition of plants at and below the wilting percentage. Tech. Bull. 29. Univ. of Arizona Agric. Exp. Stn., Tucson.

Brooks, J.R., H.R. Barnard, R. Coulombe, and J.J. McDonnell. 2010. Ecohydrologic separation of water between trees and streams in a Mediterranean climate. Nat. Geosci. 3:100-104. doi:10.1038/ngeo722

Burgess, S.S.O., M.A. Adams, N.C. Turner, and C.K. Ong. 1998. The redistribution of soil water by tree root systems. Oecologia 115:306-311. doi:10.1007/ s004420050521

Burgess, S.S.O., and T.M. Belby. 2006. Redistribution of soil water by lateral roots mediated by stem tissues. J. Exp. Bot. 57:3283-3291. doi:10.1093/ jxb/erl085

Caldwell, M.M., T.E. Dawson, and J.H. Richards. 1998. Hydraulic lift: Consequences of water efflux from roots of plants. Oecologia 113:151-161. doi:10.1007/s004420050363

Caldwell, M.M., and J.H. Richards. 1989. Hydraulic lift: Water efflux from upper roots improves effectiveness of water uptake by deep roots. Oecologia 79:1-5. doi:10.1007/BF00378231

Cardon, G.E., and J. Letey. 1992. Plant water uptake terms evaluated for soil water and solute movement models. Soil Sci. Soc. Am. J. 56:1876-1880. doi:10.2136/sssaj1992.03615995005600060038x
Carlyle-Moses, D.E., J.S.F. Laureano, and A.G. Price. 2004. Throughfall and throughfall spatial variability in Madrean oak forest communities of northeastern Mexico. J. Hydrol. 297:124-135. doi:10.1016/j.jhydrol.2004.04.007

Chang, S.-C., and E. Matzner. 2000. The effect of beech stemflow on spatial patterns of soil solution chemistry and seepage fluxes in a mixed beech/ oak stand. Hydrol. Processes 14:135-144. doi:10.1002/(SICI)10991085(200001)14:1<135::AID-HYP915>3.0.CO;2-R

Clapp, R.B., and G.M. Hornberger. 1978. Empirical equations for some soil hydraulic properties. Water Resour. Res. 14:601-604. doi:10.1029/ WR014i004p00601

Cowan, I.R. 1965. Transport of water in the soil-plant-atmosphere system. J. Appl. Ecol. 2:221-239. doi:10.2307/2401706

Croker, J.L., W.T. Witte, and R.M. Auge. 1998. Stomatal sensitivity of six temperate, deciduous tree species to non-hydraulic root-to-shoot signaling of partial soil drying. J. Exp. Bot. 49:761-774.

Dawson, T.E. 1993. Hydraulic lift and water use by plants: Implications for water balance, performance and plant-plant interactions. Oecologia 95:565-574.

Domec, J.-C., J.S. King, A. Noormets, E. Treasure, M.J. Gavazzi, G. Sun, and S. McNulty. 2010. Hydraulic redistribution of soil water affects whole-stand evapotranspiration and net ecosystem carbon exchange. New Phytol. 187:171-183. doi:10.1111/j.1469-8137.2010.03245.x

Emerman, S.H., and T.E. Dawson. 1996. Hydraulic lift and its influence on the water content of the rhizosphere: An example from sugar maple, Acer saccharum. Oecologia 108:273-278.

Espino, S., and H.J. Schenk. 2009. Hydraulically integrated or modular? Comparing whole-plant-level hydraulic systems between two desert shrub species with different growth forms. New Phytol. 183:142-152. doi:10.1111/ j.1469-8137.2009.02828.x

Federer, C.A. 1979. A soil-plant-atmosphere model for transpiration and availability of soil water. Water Resour. Res. 15:555-562. doi:10.1029/ WR015i003p00555

Federer, C.A. 1982. Transpirational supply and demand: Plant, soil, and atmospheric effects evaluated by simulation. Water Resour. Res. 18:355-362. doi:10.1029/WR018i002p00355

Ford, E.D., and J.D. Deans. 1978. The effects of canopy structure on stemflow, throughfall and interception loss in a young Sitka spruce plantation. J. Appl. Ecol. 15:905-917. doi:10.2307/2402786

Fort, C., F. Muller, P. Label, A. Granier, and E. Dreyer. 1998. Stomatal conductance, growth and root signaling in Betula pendula seedlings subject to partial soil drying. Tree Physiol. 18:769-776. doi:10.1093/treephys/18.11.769

Gardner, W.R. 1960. Dynamic aspects of water availability to plants. Soil Sci. 89:63-73. doi:10.1097/00010694-196002000-00001

Gash, J.H.C. 1979. An analytical model of rainfall interception by forests. Q. J. R. Meteorol. Soc. 105:43-55. doi:10.1002/qj.49710544304

Gash, J.H.C., C.R. Lloyd, and G. Lachaud. 1995. Estimating sparse forest rainfall interception with an analytical model. J. Hydrol. 170:79-86. doi:10.1016/0022-1694(95)02697-N

Gerrits, A.M.J., L. Pfister, and H.H.G. Savenije. 2010. Spatial and temporal variability of canopy and forest floor interception in a beech forest. Hydrol. Processes 24:3011-3025. doi:10.1002/hyp.7712

Gomez, J.A., K. Vanderlinden, J.V. Giraldez, and E. Fereres. 2002. Rainfall concentration under olive trees. Agric. Water Manage. 55:53-70. doi:10.1016/ S0378-3774(01)00181-0

Green, S.R., B.E. Clothier, and D.J. McLeod. 1997. The response of sap flow in apple roots to localised irrigation. Agric. Water Manage. 33:63-78. doi:10.1016/S0378-3774(96)01277-2

Guswa, A.J. 2005. Soil-moisture limits on plant uptake: An upscaled relationship for water-limited ecosystems. Adv. Water Resour. 28:543-552. doi:10.1016/j.advwatres.2004.08.016

Guswa, A.J., M.A. Celia, and I. Rodriguez-Iturbe. 2002. Models of soil-moisture dynamics in ecohydrology: A comparative study. Water Resour. Res. 38(9):1166. doi:10.1029/2001WR000826

Guswa, A.J., M.A. Celia, and I. Rodriguez-Iturbe. 2004. Effect of vertical resolution on predictions of transpiration in water-limited ecosystems. Adv. Water Resour. 27:467-480. doi:10.1016/j.advwatres.2004.03.001

Guswa, A.J., and A.L. Rhodes. 2004. Wet-season throughfall in primary and secondary tropical montane cloud forests, Monteverde, Costa Rica. Paper presented at: AGU Fall Meeting, San Francisco. 13-17 Dec. 2004. Am. Geophys. Union, Washington, DC. Abstr. H54C-08.

Guswa, A.J., and C.M. Spence. 2012. Effect of throughfall variability on recharge: Application to hemlock and deciduous forests in western Massachusetts. Ecohydrology (in press). doi:10.1002/eco.281

Herkelrath, W.N., E.E. Miller, and W.R. Gardner. 1977. Water uptake by plants: II. The root contact model. Soil Sci. Soc. Am. J. 41:1039-1043. doi:10.2136/ sssaj1977.03615995004100060004x

Ivanov, V.Y., S. Fatichi, G.D. Jenerette, J.F. Espeleta, P.A. Troch, and T.E. Huxman. 2010. Hysteresis of soil moisture spatial heterogeneity and the "homogenizing" effect of vegetation. Water Resour. Res. 46:W09521. doi:10.1029/2009WR008611

Jackson, R.B., J. Canadell, J.R. Ehleringer, H.A. Mooney, O.E. Sala, and E.D. Schulze. 1996. A global analysis of root distributions for terrestrial biomes. Oecologia 108:389-411. doi:10.1007/BF00333714 
Kang, S., X. Hu, P. Jerie, and J. Zhang. 2003. The effects of partial rootzone drying on root, trunk sap flow and water balance in an irrigated pear $(P y-$ rus communis L.) orchard. J. Hydrol. 280:192-206. doi:10.1016/S0022 1694(03)00226-9

Katul, G.G., and M.B. Siqueira. 2010. Biotic and abiotic factors act in coordination to amplify hydraulic redistribution and lift. New Phytol. 187:3-6. doi:10.1111/j.1469-8137.2010.03306.x

Katul, G., P. Todd, D. Pataki, Z. Kabala, and R. Oren. 1997. Soil water depletion by oak trees and the influence of root water uptake on the moisture content spatial statistics. Water Resour. Res. 33:611-623. doi:10.1029/96WR03978

Keim, R.F., A.E. Skaugset, and M. Weiler. 2005. Temporal persistence of spatial patterns in throughfall. J. Hydrol. 314:263-274. doi:10.1016/j.jhydrol.2005.03.021

Khalil, A.A.M., and J. Grace. 1993. Does xylem sap ABA control the stomatal behavior of water-stressed sycamore (Acer pseudo-platanus L.) seedlings? J. Exp. Bot. 44:1127-1134. doi:10.1093/jxb/44.7.1127

Larcher, W. 1995. Physiological plant ecology. 3rd ed. Springer, New York.

Levia, D.F., Jr., and E.E. Frost. 2003. A review and evaluation of stemflow literature in the hydrologic and biogeochemical cycles of forested and agricultural ecosystems. J. Hydrol. 274:1-29. doi:10.1016/S0022-1694(02)00399-2

Levia, D.F., Jr., and E.E. Frost. 2006. Variability of throughfall volume and solute inputs in wooded ecosystems. Prog. Phys. Geogr. 30:605-632. doi:10.1177/0309133306071145

Lhomme, J.-P. 1998. Formulation of root water uptake in a multi-layer soilplant model: Does van den Honert's equation hold? Hydrol. Earth Syst. Sci. 2:31-40. doi:10.5194/hess-2-31-1998

Li, K.Y., R. De Jong, and J.B. Boisvert. 2001. An exponential root-water-uptake model with water stress compensation. J. Hydrol. 252:189-204. doi:10.1016/S0022-1694(01)00456-5

Liu, S. 2001. Evaluation of the Liu model for predicting rainfall interception in forests world-wide. Hydrol. Processes 15:2341-2360. doi:10.1002/hyp.264

Loustau, D., P. Berbigier, A. Granier, and F. El Hadj Moussa. 1992. Interception loss, throughfall and stemflow in a maritime pine stand: I. Variability of throughfall and stemflow beneath the pine canopy. J. Hydrol. 138:449-467. doi:10.1016/0022-1694(92)90130-N

Manderscheid, B., and E. Matzner. 1995. Spatial and temporal variation of soil solution chemistry and ion fluxes through the soil in a mature Nor way spruce (Picea abies (L.) Karst.) stand. Biogeochemistry 30:99-114. doi:10.1007/BF00002726

McClain, M.E., E.W. Boyer, C.L. Dent, S.E. Gergel, N.B. Grimm, P.M. Groffman, et al. 2003. Biogeochemical hot spots and hot moments at the interface of terrestrial and aquatic ecosystems. Ecosystems 6:301-312. doi:10.1007/ s10021-003-0161-9

Melone, F., C. Corradini, R. Morbidelli, and C. Saltalippi. 2006. Laboratory experimental check of a conceptual model for infiltration under complex rainfall patterns. Hydrol. Processes 20:439-452. doi:10.1002/hyp.5913

Mendel, M., S. Hergarten, and H.J. Neugebauer. 2002. On a better understanding of hydraulic lift: A numerical study. Water Resour. Res. 38(10):1183. doi:10.1029/2001WR000911

Milly, P.C.D. 1993. An analytic solution of the stochastic storage problem applicable to soil water. Water Resour. Res. 29:3755-3758. doi:10.1029/93WR01934

Nadezhdina, N., K. Steppe, D.J.W. De Pauw, R. Bequet, J. Cermak, and R. Ceulemans. 2009. Stem-mediated hydraulic redistribution in large roots on opposing sides of a Douglas-fir tree following localized irrigation. New Phytol. 184:932-943. doi:10.1111/j.1469-8137.2009.03024.x

Nadkarni, N.M., and M.M. Sumera. 2004. Old-growth forest canopy structure and its relationship to throughfall interception. For. Sci. 50:290-298.

Neales, T.F., A. Masia, J. Zhang, and W.J. Davies. 1989. The effects of partially drying part of the root system of Helianthus annua on the abscisic acid content of the roots, xylem sap and leaves. J. Exp. Bot. 40:1113-1120. doi:10.1093/jxb/40.10.1113

Nikodem, A., R. Kodesova, O. Drabek, L. Bubenickova, L. Boruvka, L. Pavlu, and V. Tejnecky. 2010. A numerical study of the impact of precipitation redistribution in a beech forest canopy on water and aluminum transport in a podzol. Vadose Zone J. 9:238-251. doi:10.2136/vzj2009.0083
Oliveira, R.S., T.E. Dawson, S.S.O. Burgess, and D. Nepstad. 2005. Hydraulic redistribution in three Amazonian trees. Oecologia 145:354-363. doi:10.1007/s00442-005-0108-2

Phillips, F.M. 2010. Soil-water bypass. Nat. Geosci. 3:77-78. doi:10.1038/ ngeo762

Raat, K.J., G.P.J. Draaijers, M.G. Schaap, A. Tietema, and J.M. Verstraten. 2002. Spatial variability of throughfall water and chemistry and forest floor water content in a Douglas fir forest stand. Hydrol. Earth Syst. Sci. 6:363-374. doi:10.5194/hess-6-363-2002

Richards, J.H., and M.M. Caldwell. 1987. Hydraulic lift: Substantial nocturnal water transport between soil layers by Artemisia tridentata roots. Oecologia 73:486-489. doi:10.1007/BF00379405

Rodriguez-Iturbe, I., A. Porporato, L. Ridolfi, V. Isham, and D.R. Cox. 1999. Probabilistic modelling of water balance at a point: The role of climate, soil, and vegetation. Proc. R. Soc. London Ser. A 455:3789-3805. doi:10.1098/ rspa.1999.0477

Rutter, A.J., K.A. Kershwa, P.C. Robins, and A.J. Morton. 1971. A predictive model of rainfall interception in forests: I. Derivation of the model from observations in a plantation of Cosian pine. Agric. Meteorol. 9:367-384 doi:10.1016/0002-1571(71)90034-3

Ryel, R.J., M.M. Caldwell, C.K. Yoder, D. Or, and A.J. Leffler. 2002. Hydraulic redistribution in a stand of Artemisia tridentate: Evaluation of benefits to transpiration assessed with a simulation model. Oecologia 130:173-184.

Schume, H., G. Jost, and K. Katzensteiner. 2003. Spatio-temporal analysis of the soil-water content in a mixed Norway spruce (Picea abies (L.) Karst.)European beech (Fagus sylvatica L.) stand. Geoderma 112:273-287. doi:10.1016/S0016-7061(02)00311-7

Shachnovich, Y., P.R. Berliner, and P. Bar. 2008. Rainfall interception and spatial distribution of throughfall in a pine forest planted in an arid zone. J. Hydrol. 349:168-177. doi:10.1016/j.jhydrol.2007.10.051

Shani, U., and L.M. Dudley. 1996. Modeling water uptake by roots under water and salt stress: Soil-based and crop response root sink terms. In: Y. Waisel et al., editors, Plant roots: The hidden half. 2nd ed. Marcel Dekker, New York.

Siqueira, M., G. Katul, and A. Porporato. 2008. Onset of water stress, hysteresis in plant conductance and hydraulic lift: Scaling soil water dynamics from millimeters to meters. Water Resour. Res. 44:W01432. doi:10.1029/2007WR006094

Struthers, I., C. Hinz, and M. Sivapalan. 2006. A multiple wetting front gravitational infiltration and redistribution model for water balance applications. Water Resour. Res. 42:W06406. doi:10.1029/2005WR004645

United Nations Environment Programme. 1997. World atlas of desertification. U.N. Environ. Progr., London.

Vidon, P., C. Allan, D. Burns, D.P. Duval, N. Gurwick, S. Inamdar, et al.. 2010. Hot spots and hot moments in riparian zones: Potential for improved water quality management. J. Am. Water Resour. Assoc. 46:278-298. doi:10.1111/j.1752-1688.2010.00420.x

Vrugt, J.A., M.T. van Wijk, J.W. Hopmans, and J. Šimůnek. 2001. One-, two-, and three-dimensional root water uptake functions for transient modeling. Water Resour. Res. 37:2457-2470. doi:10.1029/2000WR000027

Whelan, M.J., and J.M. Anderson. 1996. Modelling spatial patterns of throughfall and interception loss in a Norway spruce (Picea abies) plantation at the plot scale. J. Hydrol. 186:335-354. doi:10.1016/S0022-1694(96)03020-X

Yao, C., S. Moreshet, and B. Aloni. 2001. Water relations and hydraulic control of stomatal behaviour in bell pepper plant in partial soil drying. Plant Cell Environ. 24:227-235. doi:10.1111/j.1365-3040.2001.00667.x

Ziegler, A., T.W. Giambelluca, M.A. Nullet, R.A. Sutherland, C. Tantasarin, J.B. Vogler, and J.N. Negishi. 2009. Throughfall in an evergreen-dominated forest stand in northern Thailand: Comparison of mobile and stationary methods. Agric. For. Meteorol. 149:373-384. doi:10.1016/j.agrformet.2008.09.002

Zimmermann, A., B. Zimmermann, and H. Elsenbeer. 2009. Rainfall redistribution in a tropical forest: Spatial and temporal patterns. Water Resour. Res. 45:W11413. doi:10.1029/2008WR007470 